\title{
La estética del poema integral en Enrique Verástegui y Juan Ramírez Ruiz
}

The aesthetics of the integral poem in Enrique Verástegui and Juan Ramírez Ruiz

\author{
Biviana Hernández ${ }^{1}$, Luis Fernando Chueca ${ }^{2}$ \\ ${ }^{1}$ Universidad Academia de Humanismo Cristiano. \\ Correo electrónico: bhernandezo@docentes.academia.cl \\ ${ }^{2}$ Pontificia Universidad Católica del Perú. \\ Correo electrónico: lchueca@pucp.edu.pe
}

El artículo aborda la estética del poema integral a partir de los postulados del proyecto neovanguardista del movimiento Hora Zero del Perú, en los poemarios: Angelus Novus (1989; 1990), de Enrique Verástegui y Las armas molidas (1996), de Juan Ramírez Ruiz, este último co-fundador del grupo en 1970. El propósito es analizar, desde el punto de vista comparativo, la dimensión estética del poema integral a partir de las propuestas discursivas que ambos textos ofrecen en el marco de una poética intergenérica de carácter utópico y total.

Palabras clave: Poema integral, Enrique Verástegui, Juan Ramírez Ruiz, Hora Zero, poesía peruana.

This article addresses the aesthetics of the integral poem from the postulates of neo-avantgarde project of Movimiento Hora Zero of Peru in the poetry books: Angelus Novus $(1989 ; 1990)$ of Enrique Verástegui and Las armas molidas (1996) of Juan Ramirez Ruiz, the latter co-founder of the group in 1970. The purpose is to analyze, from a comparative point of view, the aesthetic dimension of the integral poem from the discursive proposals that both books offer in the framework of an intergeneric poetic of utopian and total carácter.

Keywords: Integral poem, Enrique Verástegui, Juan Ramírez Ruiz, Hora Zero, Peruvian poetry

Este artículo forma parte del proyecto FONDECYT de Postdoctorado $\mathrm{N}^{\circ}$ 3130628, "Poesía y neovanguardias: textualidades para un nuevo repertorio" (P. Universidad Católica de Chile), del cual Biviana Hernández ha sido responsable, y de la tesis de doctorado en Literatura de Luis F. Chueca, "Nación y violencia en la poesía peruana (1983-2014)" (P. Universidad Católica de Chile). Partes del presente texto han aparecido, aunque sin abordar como eje la poesía integral, en Hernández 2012 y Chueca 2014a y 2014b. 


\section{LA ESTÉTICA DEL POEMA INTEGRAL: UtOPíA Y TOTALIDAD}

Hora Zero fue un movimiento poético de vanguardia conformado por escritores que se autoproclamaron, desde el manifiesto y la declaración pública, como iniciadores de un nuevo momento poético en el Perú ${ }^{1}$. Su gesto, no solo de reacción sino también de rechazo y negación de casi toda la tradición literaria nacional, buscaba reactivar, desde el contexto del que emergía, los principios ideológicos de las vanguardias históricas: acción política, diálogo arte-vida, transformación de la realidad. Sobre la base de estas premisas, HZ se articuló en torno a la posibilidad revolucionaria de la poesía, al uso del "lenguaje vivo de las calles" y a la configuración en los poemas de sujetos populares, gesto que sería retomado una década más tarde vía el descentramiento de los sujetos de escritura y el "discurso esquizoide" (Mazzotti), con la irrupción del Movimiento Kloaka, que puede considerarse como un nuevo estallido neovanguardista y una nueva (y última) radicalización de la línea conversacional consolidada en el Perú a mediados de los sesenta con voces como las de Luis Hernández, Rodolfo Hinostroza, Antonio Cisneros o Mirko Lauer, en quienes ya se expresaban con claridad algunos de los rasgos fundamentales de la modernización poética peruana de la segunda mitad de siglo XX:

poesía de rasgos coloquiales y narrativos, con interés por los proyectos totalizantes de la tradición anglosajona y francesa (Pound, Eliot, Perse); poesía de crítica del entorno socioeconómico desde un distanciamiento irónico de corte brechtiano; poesía, en fin, de la cotidianeidad y la exploración del rol del individuo en una sociedad del llamado Tercer Mundo, en constante pugna cultural con los productos y visiones de los países de mayor desarrollo capitalista; poesía de solidaridad política con la imagen de la Cuba revolucionaria y el compromiso, en el texto, con una multifacética labor de diseño verbal que empieza en casa (López Degregori y O’Hara 1998: 15)².

Si bien en los llamados "poetas de los sesenta" hubo ruptura, conciencia de la marginación frente a los espacios centrales de la cultura y un pronunciado afán de ironía como postura crítica, en sus prácticas de escritura, en general, ellos operaron, como señala Ricardo Falla (1990), sobre el convencimiento de la literatura como especificidad, esto es, desde una valoración consensual de un español culto como norma literaria. Los poetas que comenzaron a publicar hacia 1970, y sobre todo los de HZ, procuraron, por su parte, fracturar la continuidad de una tradición que asumía la literatura como claustro de espacios cerrados y elitistas (Oviedo). En ese sentido, asumieron el legado conversacional desde la perspectiva de la estética del "poema integral"3 que daba cabida

Jorge Pimentel aclara que el nombre de Hora Zero no corresponde a un homenaje al poema homónimo de Ernesto Cardenal, sino al interés de manifestar con él la idea de "aquí empezamos". Un comienzo ab ovo, como planteara Oviedo: "antes que ellos, nada o poco menos que nada: después de ellos, ¿qué? Entre el caos y la Apocalipsis, su palabra" (1973: 09). En adelante, nos referiremos al movimiento con la sigla HZ.

2 Debe dejarse constancia de que, si bien en este proceso resultan hegemónicos los desarrollos poéticos vinculados con la dicción conversacional, no son las únicas propuestas. En estas tres décadas pueden reconocerse otros caminos que obligan a una mirada más compleja de la poesía de la segunda mitad del siglo XX en el Perú: entre ellos Juan Ojeda, Carlos López Degregori, Luis La Hoz y Magdalena Chocano, por ejemplo.

3 Esbozada por Juan Ramírez Ruiz, al final de su poemario Un par de vueltas por la realidad (1971), como "Estética del Movimiento HZ" y asumida de ese modo por el colectivo. 
a todo lo vivo, pues "[t]odo lo que late y se agita tiene derecho al rastro" (Ramírez Ruiz y Pimentel 1970: 9). El exacerbado vitalismo, la vocación "exteriorista” y la atención a sujetos y voces diversas del castellano peruano que se desprendían de ello, así como la despreocupación por la perfección o la belleza formal y el impulso descentralizador reflejado en la existencia de bases de Hora Zero en diversas regiones del país, revirtieron en una ampliación del metatexto vigente en la poesía peruana. ${ }^{4}$

La emergencia del grupo se vio estimulada por el contexto efervescente de movilizaciones sociales y migraciones internas, que — en tensión con, pero a su vez dinamizadas por la prédica y los gestos de la dictadura militar de Velasco Alvarado 5 -, transformaron el rostro de la sociedad peruana y pusieron en jaque, al menos temporalmente, al poder oligárquico en el país. Los poetas de HZ, a través de sus explosivas proclamas, que pretendían esclarecer y corregir los alcances de lo que sus miembros consideraban el proyecto fallido de una poesía basada en el repertorio lingüístico de la "clase letrada" limeña, declararon obsoleta toda la tradición poética (a excepción de César Vallejo, y de los poetas de los sesenta Javier Heraud y Edgardo Tello, muertos a raíz de su participación en acciones guerrilleras en dicha década), y decretaron el inicio de un nuevo tiempo que se iniciaba con ellos como protagonistas:

Necesario es pues, dejar las nubes en su sitio. Si somos iracundos es porque esto tiene dimensión de tragedia. A nosotros se nos ha entregado una catástrofe para poetizarla. Se nos ha dado esta coyuntura histórica para culminar una etapa lamentable y para inaugurar otra más justa, más luminosa (Ramírez y Pimentel 1970: 9-10).

Las palabras inaugurales de los horazerianos se pueden poner en diálogo con otras como las de El corno emplumado en México, con las que, a comienzos de los sesenta, este grupo apostaba también por la fundación de una nueva era para el arte y la creación poética:

Sabemos que un nuevo mundo se elabora, y que estamos en el centro de un movimiento que está revolucionando la poesía hispanoamericana [...] Sólo que este movimiento es mucho más que eso: significa el fin de los tiempos anunciados por las Escrituras, el principio de una nueva historia y el momento en que se hunde para siempre un mundo y una concepción del mundo envejecida, para dejar lugar a una especie humana más evolucionada $[\ldots]$ estamos al comienzo de un Renacimiento. /[...]/ Es esta una poesía que nos invita a vivir, a nacer de nuevo... (1962).

\footnotetext{
Lo que no impide ver antecedentes: "[l]a evidencia de que el nuevo escenario forma parte de un proceso mayor iniciado en la década previa, puede encontrarse, por ejemplo en los inocultables parentescos entre Verástegui e Hinostroza (montaje poético, collage, cosmopolitismo); entre Mora y Cillóniz con el Cisneros de Comentarios reales (1965); entre la jerga de Manuel Morales, Pimentel y Ruiz y la norma barrial de Luis Hernández; entre la concisión de Watanabe y la de Marco Martos, y en alguna medida entre la geografía urbana de los 70 y la Ciudad de Lima (1968) de Lauer." (Chueca 2006: 33).

5 Entre 1968 y 1975 tuvo lugar el gobierno reformista del General Juan Velasco Alvarado y las Fuerzas Armadas de Perú (autodenominado Gobierno Revolucionario de las Fuerzas Armadas), que intentó poner en práctica un proyecto nacional de orientaciones progresistas, mediante una política de nacionalizaciones y legislaciones pro-campesinas. Lo que se tradujo, entre sus principales obras, en la aplicación de la reforma agraria, el reconocimiento de la diversidad cultural y la oficialización del quechua, junto a la reforma de la empresa, la estatización del petróleo, así como de las más importantes empresas mineras. Todo ello en paralelo a la difusión de un planteamiento ideológico nacionalista que hizo de la figura del rebelde Inca Túpac Amaru II — ejecutado en 1781 por los españoles, tras liderar una masiva rebelión contra el orden colonial— el ícono oficial del gobierno militar. Cf. Matos Mar 1984.
} 
En realidad, se debe reconocer que lo propuesto por HZ no solo profundizaba la dinámica ya iniciada en los sesenta en el Perú, sino que participaba de una constelación de propuestas que en todo el subcontinente, desde inicios de dicha década y hasta fines de los setenta, y con acentos o énfasis diferenciados según su contexto de aparición, pugnaban por algo semejante ${ }^{6}$. Es posible mencionar, por citar solo algunos, El techo de la ballena (Venezuela, 1961-1968), Tzánzicos (Ecuador, 1962-1969), Tribu No (Chile, 1966-1969), Tucumán Arde (Argentina, 1968), Infrarraelistas (México, 1975-1977); La Sagrada Familia (Perú, 1977-1979)7. Todos ellos constituyeron una estructura de sentimiento (Williams), que, como exclamaba Saúl Yurkievich en "Los disparadores poéticos" (1984), involucraba a los poetas jóvenes de América Latina:

Sentimos urgencia por reubicarnos estéticamente, del mismo modo que la coyuntura histórica que vivía el continente nos compulsaba a un replanteo político [...] Queríamos devolverle a la poesía la plenipotencia de su capacidad de manifestación; queríamos sacarla del ensimismamiento psicológico y de la estrechez sociológica, para reinstalarla en la actualidad candente, convulsionada y acelerada de América Latina por el estallido de una serie de movimientos liberadores. Queríamos volverla a ligar con la lengua viva y con el mundo cotidiano. De ahí esa creciente de coloquialismo y anecdotario, que la prosifica y contamina de narratividad [...] Queríamos devolverle el talante humorístico y el talento lúdico [...]; queríamos desacralizarla, desacartonarla, restituirle la plasticidad, la fluidez, la pluralidad, dotarla de la máxima amplitud de recursos para que pudiese decir la totalidad de lo decible (46).

En el marco de este espíritu colectivo por ampliar los límites del lenguaje poético, los poetas de $\mathrm{HZ}$ asumieron con exacerbado ímpetu el compromiso de un mundo y una poesía nuevos, haciendo suyo el proyecto de una "toma de situación y conciencia" que llamaba a poner en obra los postulados del deber ético del poeta en el cruce entre poesía y sociedad, arte y vida:

En esta época llena de desfallecimientos y omisiones la toma de situación y conciencia es ineludible. Y esto se edita a consecuencia de la necesidad de manifestarnos como hombres libres y como escritores con una nueva responsabilidad, con una nueva actitud ante el acto creador, ante los hechos derivados de una realidad con la que no estamos de acuerdo. (Ramírez Ruiz y Pimentel: 7).

Se trata ahora de escribir la poesía de la vida del pueblo en los términos justos en que se da esa vida, es decir vitalmente: vivaz, vital y dinámica, con un ritmo ágil y fluyente y con un lenguaje directo, sencillo, duro y sano (Ramírez Ruiz 1971: 115).

No es el propósito de este ensayo comentar los avatares del proyecto horazeriano durante sus décadas de existencia ${ }^{8}$. Basta con señalar, para nuestros propósitos, que

${ }_{6}$ En este escenario, podrían reconocerse relaciones productivas con las experimentaciones de la poesia totale de Adriano Spatola, que buscaba, entre los años 60 y 70, romper las fronteras entre los diversos lenguajes artísticos posibles de aparecer en el poema; lo mismo que con algunas de las propuestas de literatura combinatoria que los miembros del Taller de Literatura Potencial (OuLiPo), por ejemplo, Raymond Quenau o Georges Perec, entre otros, venían desarrollando desde los años 60 .

7 Para ver las relaciones a nivel de campo cultural latinoamericano entre estas distintas agrupaciones y colectivos, véase Galindo 2013.

8 Sobre este punto, Mora (2009) ofrece una versión de parte sobre los procesos en el desarrollo del colectivo. Otras 
a la primera etapa de HZ (1970-1973) siguió otra, iniciada en 1977, en la que Juan Ramírez Ruiz, uno de sus fundadores y autor principal de los manifiestos iniciales y de la estética del poema integral, no participó por considerar que el colectivo al que se convocaba en ese momento, en circunstancias muy distintas a las de la aparición original de $\mathrm{HZ}$ en el campo literario, no podía verse como la continuación directa de la misma experiencia ni era, en consecuencia, el mismo grupo que insurgió con virulencia en 1970, por lo que no le correspondía llevar el mismo nombre ${ }^{9}$. Lo que nos interesa, más bien, es ofrecer una mirada sobre la continuidad de otra dimensión del proyecto colectivo, la que corresponde a la estética del poema integral, en dos de los más conspicuos miembros de HZ de la primera hora: Juan Ramírez Ruiz y Enrique Verástegui. Ambos poetas han sido quienes más han ampliado o replanteado las coordenadas en las que se suele ubicar dicha poética.

Como es conocido, la comprensión habitual acerca de la poesía integral proviene de "Poesía integral (notas acerca de una hipótesis de trabajo) / Primeros apuntes sobre la Estética del Movimiento Hora Zero", texto que Ramírez Ruiz incluyó a modo de colofón en Un par de vueltas por la realidad (1971), su primer poemario. Allí Ramírez Ruiz afirmó que "[1]a vastedad y complejidad de la experiencia humana de este tiempo es tal que no puede ser registrada cabalmente por una poesía estrictamente lírica. Solo una poesía que integre y totalice puede incorporar y ofrecer un válido registro de la experiencia de este tiempo sacudido por todo tipo de conmociones" (1971: 110). Lo narrativo y la dimensión dramática debían incorporarse al registro poético, logrando un efecto de totalización,

donde se amalgame el todo individual con el todo universal. Es decir, materia de un poema integral es la realidad acontecida y aconteciente; y que adviene en sucesos como expresión de los enfrentamientos de las clases en pugna. Esta materia se expresa en una emoción y sus efectos concomitantes; una idea y sus efectos concomitantes, y derivados llenos de energía movilizante.

$\mathrm{Y}$ en este punto cabe decir que el uso directo del tiempo, del espacio, de gente, de hechos que se protagonizan o no [...] y también recuerdos, anhelos, sensaciones, necesidades, situaciones de todo nivel son solo elementos de la materia de un poema integral (Ramírez Ruiz 1971: 110).

Enfatizaba de este modo que la poesía integral debía “comenzar abriendo el poema y dejarlo abierto es consignar la Realidad. Es decir todo poema integral intentará postular el ritmo y el sentido del nuevo estilo de vida" (111). Entre las plasmaciones más claras de estos planteamientos están los poemas finales de los primeros libros de los dos fundadores de HZ: "Sinfonía en Marlene" en Kenacort y Valium 10 (1970) de Jorge Pimentel, y "Un par de vueltas por la realidad" del homónimo poemario de Ramírez Ruiz. Se trata de extensos poemas de versos amplios, impregnados de exclamaciones y mayúsculas, apelaciones e imprecaciones, registros precisos

apreciaciones al respecto pueden revisarse en Sánchez Hernani 1981, Chueca 2006 y Torres Rotondo e Yrigoyen 2010.

9 Se trataba - afirmó poco después - no solo de un proyecto distinto, sino incluso de un simulacro que se "ha convertido en antípoda del proyecto original", puesto que "[c]onfirma el usufructo para fines personales de un proceso colectivo que tenía como ideal supremo la objetivación en la historia de las aspiraciones más profundas del espíritu humano: el Amor, la Libertad, la Poesía". Ramírez Ruiz expresa estas ideas en el manifiesto "Palabras urgentes 2" (1980); ver al respecto Paolo de Lima (2014). 
de fechas y lugares, expresiones líricas, fragmentos narrativos, diálogos, dichos populares, referencias históricas y, entre ello, huellas de cultura letrada.

Siguiendo estas pistas, fueron varios los poetas que escribieron textos de gran interés, aunque también hubo otros que evidenciaron los límites a los que puede conducir la aplicación mecánica y repetitiva de un postulado. Al mismo tiempo, el propio Ramírez Ruiz continuó investigando y profundizando algunas posibilidades que parecían anunciarse, aunque todavía sin mayor desarrollo, en ciertas menciones de "Poesía integral", como las que aludían a la "energía movilizante" o "las situaciones a todo nivel" presentes en los poemas integrales, así como nuevas perspectivas que ampliaban el concepto. Estas parecen ser las que articulan un libro tan distinto de $U n$ par de vueltas por la realidad como Vida perpetua (1978), su segundo poemario, en que cobran protagonismo la poesía combinatoria, el interés por la cibernética y la atribución al lector de la condición de coautor, no solo a partir de sus posibles interpretaciones, sino de su participación en la producción del texto. Luego, con Las armas molidas (1996), llevó más lejos la comprensión de la poesía integral, a través de la aplicación en su escritura de una serie de principios que propone como operantes en la "lengua hanan", sistema de bases indígenas y multidimensionalidad que creó como invitación a que los pueblos del Perú desarrollen modos de comunicación y pensamiento "ontológicamente nuestro[s]". A propósito, señaló Ramírez Ruiz en una entrevista en 2006 que "[e]n la poesía integral se convocó a todos los componentes posibles, visuales y auditivos, que constituyen una interrelación que entre ellos pueden emitir un sistema según una regulación eficaz. Entonces, allí estaba desatada la nueva poesía” (Ojeda 2008).

También Enrique Verástegui propuso un radical ensanchamiento de la comprensión inicial de la poesía integral, tanto a través de su trabajo poético como en su estudio El motor del deseo (1987). En su caso, parece sostenerse que la revolución social, afirmada desde sus primeros momentos por HZ, debía ir unida a una revolución del lenguaje y a una revolución de los cuerpos; planteamiento con el cual el autor pasaba a formar parte del metatexto del poema integral, el cual quedaría plasmado en la publicación de su primer libro, En los extramuros del mundo (1971), desde el empleo del registro conversacional, que buscaba dejar constancia de los "vicios pandémicos" de la sociedad moderna periférica de su tiempo, y de la modernidad periférica en el Perú en particular, para avanzar, luego, hacia el registro de lo interdisciplinario entre poesía y otras artes (la pintura, la música), otros lenguajes, saberes y disciplinas (principalmente las matemáticas), y otras formas de pensamiento, como el misticismo; Es en Monte de goce (1991) y en Angelus Novus (1989, 1990) en donde se observa, más claramente, este desplazamiento.

Las páginas que siguen apuntan, a partir de lo señalado, a indagar en las propuestas que amplían la concepción del poema integral en libros de ambos poetas. Nos centraremos fundamentalmente en Angelus Novus de Verástegui y en Las armas molidas de Juan Ramírez Ruiz.

\section{EnRique Verástegui: la poesía como VATicinio e ILUMinación}

Bajo la forma de un horizonte utópico, la condición integral del poema en la escritura de Enrique Verástegui tiene que ver con una serie de operaciones textuales y metatextuales de autoconstrucción de la figura social del poeta, a partir de 
procedimientos neovanguardistas que problematizan la heterogeneidad semiótica de su obra, producida mediante la imbricación de géneros, contenidos, lenguajes y formatos, provenientes de distintas artes, disciplinas y teorías, en un esfuerzo por recogerlo, nombrarlo y reescribirlo todo (Medo y Zurita 2004). Lo que el propio Verástegui entendía como la mezcla entre "ciencia y sensibilidad, ciencia y poesía o con materias que tienen que ver con la sociología, con el feminismo, con la teoría de la novela, con la lingüística, con la economía, teniendo como fondo el fin y el comienzo de un nuevo milenio" (Guillén 2015).

En este marco, una de las cuestiones que resultan más interesantes del proyecto de obra de Enrique Verástegui, "poeta, revolucionario y loco", es la tensión existente entre la perspectiva moderna de su escritura, que asigna al poeta la función de vidente, vate o profeta, y el carácter neovanguardista de su registro experimental, inflamado de proclamas y retórica, en el que sobresale el presupuesto del alarde como condición de sujeto periférico descentrado, "un marginal que toma por asalto la ciudad", remitiéndose, en el terreno del lenguaje, a elementos romántico-modernos, "como el sistema dodecafónico o composiciones a lo Kandinsky" (Guillén 2015: 27), que sustentan su carácter experimental y rupturista. Verástegui entiende al poeta como un sujeto marginado de la sociedad, como un yo "cosificado y nominal", cuyas preocupaciones deslindan en un imaginario romántico que lo vincula con las corrientes simbolistas, herméticas, surrealistas, "[p]ero se configura a grandes rasgos en una elaboración romántica" (Guillén 2015: 27-28). Sobre su obra reunida en el voluminoso Splendor ${ }^{10}$, Alba Delia Fede comenta, al respecto, que su desarrollo teórico es moderno cuando se trata de varios libros que conforman un único proyecto, elaborado, desde una comprensión de lo clásico, como un modelo perdurable, consciente de haber superado sus lazos con el pasado y la tradición; “[e]s moderna, finalmente, porque toda utopía lo es" (Fede 2013: 16).

\section{Angelus NovUs: POEMA-PROCESO, JUEGO DE ESTRUCTURAS, CONOCIMIENTO Y EXPERIENCIA}

Conocida es la novena tesis de Filosofía de la historia de W. Benjamin, donde interpreta el "Angelus novus" de Paul Klee:

Se ve en él a un Ángel al parecer en el momento de alejarse de algo sobre lo cual clava su mirada. Tiene los ojos desencajados, la boca abierta y las alas tendidas. El ángel de la Historia debe tener ese aspecto. Su cara está vuelta hacia el pasado. En lo que para nosotros aparece como una cadena de acontecimientos, él ve una catástrofe única, que acumula sin cesar ruina sobre ruina y se las arroja a sus pies. El ángel quisiera

Ética es el nombre que recibe el conjunto de las obras más connotadas de Enrique Verástegui: Monte de goce (1991), Taki Onqoy (1993), Angelus Novus (I y II, 1989-1990) y Albus (1995), los cuatro libros de la Ética que en 2013 Verástegui reunió en el volumen Splendor (1972-1994). Para Paul Guillén, Splendor clausura el ciclo neovanguardista en la obra de Verástegui, que él identifica en tres periodos: “A) En los extramuros del mundo y Praxis, asalto y destrucción del infierno, donde el locutor personaje es un sujeto descentrado, periférico y marginal. B) El proyecto Splendor, antes llamado Ética [...] donde se transita el mundo del pecado, las drogas, los movimientos insurreccionales, la unión de pareja en un sentido místico, incluso aproximaciones desde el taoísmo, para terminar esos recorridos en aforismos en conjunción con las ideas de Wittgenstein y el I Ching. C) Ensayo sobre ingeniería, Teorema de Yu y Teoría de los cambios, libros de perspectiva interiorista o contemplativa que condensan experiencias en torno a la ciencia, la filosofía y las matemáticas." (2015: 19). 
detenerse, despertar a los muertos y recomponer lo despedazado. Pero una tormenta desciende del Paraíso y se arremolina en sus alas y es tan fuerte que el ángel no puede plegarlas... Esta tempestad lo arrastra irresistiblemente hacia el futuro, al cual vuelve las espaldas mientras el cúmulo de ruinas sube ante él hacia el cielo. Tal tempestad es lo que llamamos progreso (2007: 78).

El cuadro filosófico - Klee interpretado por Benjamin — no solo sirve de epígrafe al inicio del primer tomo del Angelus Novus (1989), sino también de intertexto al proyecto integral de su obra en tanto que interpretación de la historia cultural de Occidente, $y$, al mismo tiempo, de metatexto, en circunstancias que es usado para justificar la imagen moderna del poeta, Enrique Verástegui, como el ángel de la Anunciación y la Historia. Esto último explica, también, la inscripción autobiográficotestimonial del poemario como una colección de apuntes, un diario de vida, una memoria, un cuaderno de viajes o un libro de notas, donde el poeta se autoconstruye como el principio activo de una poiesis autoconsciente (Fede 2013), mediante múltiples referencias literarias, históricas y culturales, que el hablante del texto va organizando en las distintas secciones del libro, en forma de citas, anotaciones, comentarios y reflexiones; secciones que el autor textual denomina "meditaciones", "precisiones", "examen", "síntesis" y "estudios"; tipologías discursivas que abarcan los más diversos aspectos y dimensiones del conocimiento y la experiencia humana y social, y a través de las cuales la construcción de subjetividad encarna una serie de operaciones específicas y complejas que dan lugar, simultáneamente, a varios "ego" o a varias "posiciones-sujeto" (Foucault 1999: 343).

Verástegui es, así, el poeta moderno, lingüista, matemático, gramático, semiótico, científico, filósofo, místico, un sujeto desorbitado y romántico que quiere ocupar todas las instancias de la locución, estableciendo para ello un circuito de recorrido vital, un "elenco de huellas operadas por el hombre integral" (Fede 2013: 19), reveladoras de un profundo deseo de conocimiento que desencadena procesos racionales, afectivos y simbólicos (López Soria 2001). Procesos que en la obra de Verástegui se hacen presentes desde los espacios distópicos de la urbe moderna (En los extramuros del mundo; Praxis, asalto y destrucción del infierno), pasando por los procesos históricos que sirven de referente y contexto a su producción de corte más social (La educación formal; Taki Onqoy), a las indagaciones más introspectivas en torno al cuerpo, el erotismo y la sexualidad, el misticismo, la filosofía oriental, las artes, las humanidades, la tecnología y las ciencias, que encontramos en los dos tomos de Angelus Novus, así como también en Monte de goce y Albus.

Atravesada por las contradicciones y limitaciones de estos procesos, el proyecto del poema integral en Enrique Verástegui va a sostener una profunda confianza en la capacidad de testimoniar, reivindicar y transformar de la palabra poética; asumiendo su ejercicio como un acto de salvación, toda vez que en ella "la palabra sana y la escritura purifica" (Frisancho 1990:118). Verástegui inscribe cada una de las partes o etapas de su obra en un proyecto total (primero, llamado Ética; luego, Splendor), acorde con el recorrido vital de la experiencia como designio o interpretación estética e ideológica de la cultura humana; y este es, precisamente, el "designio" de Angelus Novus como un proyecto utópico radical.

Para Ricardo González Vigil, Angelus Novus $(1989,1990)$ es "la expresión mejor lograda de Verástegui en la apuesta por una obra abierta y totalizante hacia la realidad 
y la vida, y el empleo del lenguaje como revelación, iluminación, profecía, "angelus" perpetuamente "novus"' (1999: 7). El libro se articula como una propuesta integral del saber histórico, literario y filosófico de la humanidad, de acuerdo con la búsqueda utópica del poeta de anunciar la realización total tanto de la pareja erótica (cantar de los cantares), como de la sociedad comunitaria (revolución social) y del signo verbal (la palabra); "un mensaje salvífico, embriagado de esperanza" (8), sostenido en el proyecto de lograr una comunicación ecuménica y humanizadora: "un taller de Eros, de Utopía y de anti-Babel. Un concierto que hace estallar el flujo vital que conquista la luz, la felicidad y la plenitud en lo erótico, lo social y lo verbal" (González Vigil 1999: 8).

La elaboración del poema integral en Verástegui tiene que ver, entonces, con las múltiples relaciones entre lo erótico, lo social y lo verbal, que, en su forma discursiva, van trazando los distintos registros entre lo autobiográfico, lo testimonial, lo poético y lo ensayístico; un cruce de géneros y lenguajes que conforman, al decir de Paul Guillén, el "juego de estructuras" de la obra verasteguiana, que abarca desde la pluralidad visual y tipográfica a múltiples formatos y registros escriturales: dibujos, diagramas, partituras, ecuaciones, figuras geométricas, entre otros. El sujeto hiperculto de la enunciación va desplegando, así, las formas o estructuras del libro de acuerdo con una dinámica entre experiencia y lenguaje, vida y poesía, conocimiento y alarde, para darle sentido a la figura del poeta moderno-vanguardista y, en consecuencia, a su confianza tanto en el compromiso del hombre con principios éticos y morales, como en la superación crítica del lenguaje de la poesía y la historia como relatos o discursos culturales. El "ángel Enrique” enfrenta aquí la tormenta inevitable del progreso (del lenguaje y la historia), a la cual el Angelus novus de Klee daba la espalda.

Desde poemas-ensayo ("Ensayo sobre la reciprocidad de las oposiciones continuas"), o poemas-estudio ("Estudios sobre flores con pájaros y amaneceres de primavera), pasando por su "Cuaderno de viajes: París 1978-1980", hasta el "Examen retrospectivo del arte moderno" y su "Tríptico: Homenaje a Hieronimus Bosh", el poeta-iluminado de Angelus Novus propone distintas reflexiones a través de múltiples estructuras discursivas, sobre el arte y la poesía, la escritura y la lectura, el cuerpo, la sexualidad, la historia, la filosofía, las matemáticas, las ciencias, haciendo del poema un espacio de pensamiento y reflexión sincréticos, de acumulación y superposición de experiencias de lectura, de teorías y saberes, mas no siempre dialogantes o con un sentido de unidad entre ellos. En Verástegui, la propuesta de una poesía integral, tal como lo planteara Ramírez Ruiz, tuvo que ver, en principio, con el intento de destruir la sintaxis tradicional que promovían los miembros de HZ, pues si algo tuvo en común con este grupo fue la idea de destruir un lenguaje que consideraba caduco:

por un lado, una retórica nacida en el siglo XIX, vigente en la primera parte del siglo XX; por otro, el lenguaje elitista y distanciado de la generación del sesenta [...] Para Verástegui, las preocupaciones de Hora Zero son solo un punto de partida en un proyecto más ambicioso, porque lo que finalmente le interesa, más allá de la forma, es destruir un lenguaje y al mismo tiempo destruir los límites impuestos entre los géneros literarios (Villacorta 2011: 7).

De modo que, en su caso, lo integral implicaría también, y quizás sobre todo, la preocupación por la construcción del poema como forma o estructura, "por la alucinación en la textura del verso, por el dominio técnico perfecto del poema" (Luchting 1977: 331). 
De comienzo a fines de los 80, Verástegui logró complejizar notoriamente su propuesta estética al enfatizar la perspectiva de lo integral desde la multidimensionalidad del lenguaje poético. En Angelus Novus esto es claro y, quizás, sea el ejemplo más radical de su apuesta y realización del poema integral. En este dio origen a un texto genérica y epistemológicamente heterogéneo y complejo, como resultado de un juego de estructuras de carácter lúdico-experimental; así lo vemos en el planteamiento de sus ejercicios lógico-matemáticos o los juegos de sentido que apelan a un lector-autor potencial de la escritura, pues en este libro es el lector, finalmente, quien debe completar y resolver los problemas que los enunciados del texto plantean, como si se tratara de un poema-proceso ${ }^{11}$, a la usanza concretista, en permanente construcción y deconstrucción de sí mismo. Desde el lenguaje matemático, por ejemplo, presente de manera transversal en las distintas secciones del libro, el sujeto plantea el poema como una "combinatoria de signos", donde los signos numéricos invitan a reflexionar sobre las relaciones entre lenguajes y códigos verbales y no verbales; y entre ciencias y saberes comúnmente disociados. El poeta quiere encontrar un lenguaje común para el arte y las ciencias, un lenguaje donde poesía y matemáticas, por ejemplo, compartan un mismo código y un mismo alfabeto con que nombrar los grandes enigmas y dilemas de la existencia humana, el amor, el cuerpo, la sexualidad, la religión.

Si el poema integral de Verástegui busca estimular procesos afectivos, racionales y simbólicos, de la misma forma asume el conocimiento como un proceso multidimensional que desde lo cognitivo incluye lo intuitivo, afectivo y emocional. El signo verbal no basta, entonces, para explicar "la totalidad de lo viviente" que buscaba el proyecto integral en los inicios de HZ; y, tampoco, para dar cuenta de todas las posibilidades de expresión de los lenguajes del arte y las ciencias, en el marco de una poética integral de lenguajes y saberes de distinta factura. No obstante, la relación entre matemáticas y poesía, si bien es una de las formas de expresión de una estética de lo integral, en el caso de Verástegui, más bien, esta limita sus posibilidades de recepción y/o decodificación cuando excluye a un tipo de lector: "aquel que no esté preparado en términos de conocimientos, por una parte, y que no tenga una sensibilidad para apreciar el arte, por otra" (Villacorta 2011: 6). Verástegui opera un juego de estructuras entre signos verbales y signos numéricos en tanto códigos de uso restringido de la lengua; un juego donde el hacer poético es la contraparte del saber científico, pues aquí el poema se vuelve equivalente a un trabajo que requiere competencias cognitivas de distinto orden: saber, hacer, identificar, nombrar, combinar, relacionar. Lo cual, como recurso o estrategia, sugiere que el pensamiento y sus infinitas posibilidades se activa cuando los distintos lenguajes/saberes actúan en conjunto, de manera inclusiva y simultánea; de suerte, por ejemplo, que una operación matemática, cual "teorema del universo", sea capaz de contener una imagen verbivocovisual ${ }^{12}$ del mundo de la experiencia.

11 En el contexto de la poesía concreta, la noción de Poema/Proceso (1967) refiere al texto poético entendido como un proceso en el cual el lector, espectador/operador, podría modificar sus elementos: agregar, borrar, ensamblar, montar, etc., realizando una lectura diferida o en movimiento del poema de acuerdo con los fragmentos o partes que eligiese para su (re)construcción. Cf. Noigrandes 4 en De Sousa 1978.

12 En el ámbito de la poesía concreta, la categoría de "verbivocovisual" alude a un entramado de aspectos verbales, vocales y visuales, que los poetas concretos buscaban generar a través de la pluridimensionalidad del texto poético. Cf. Noigrandes 4 en De Sousa 1978. 
En las primeras secciones de Leonardo (Angelus Novus II, 1990), Verástegui desarrolla una serie de estructuras verbovisuales, que sintetizan sus iniciales pero ya ambiciosas reflexiones en torno al arte (la pintura, principalmente), la escritura y la sexualidad, mezclando en un mismo nivel de lenguaje la experiencia vital del hablante (sobre todo, sus dilemas y obsesiones sexuales) con sus fuentes y referencias eruditas de variada procedencia (historia, filosofía, lingüística). Leonardo, publicado en 1988 en las ediciones del Instituto Nacional de Cultura del Perú y, más tarde, incluido en el segundo tomo de Angelus Novus, es una suerte de arte amatorio donde el cuerpo es el lugar de la utopía, la armonía y la realización plenas del ser humano. Se plantea como un "tratado de la experiencia" en las dimensiones que abarca la cotidianeidad de lo urbano, lo personal y lo social, la intimidad del placer y el goce sexuales, ejes fundamentales del misticismo erótico que el sujeto busca ejercitar poéticamente como vía de conocimiento y registro, nuevamente, de una de las más importantes dimensiones de la totalidad de la experiencia humana.

El texto se divide en un conjunto serial de poemas narrativos numerados, muchos de los cuales se inician con un sintagma inicial sobre el tema del cuerpo, el amor o la sexualidad, en oraciones simples que van variando su enunciado de acuerdo con la progresión numérica de los textos, pero en ellos, finalmente, no se sale de este universo temático; todo es cuerpo, amor, sexualidad. No obstante, lo que se torna complejo es la dimensión gráfica y visual que van adquiriendo los poemas en el proceso de expansión y desborde de la palabra. La sección siete de Leonardo, por ejemplo, "Estudios filosófico-matemáticos para la aplicación de computadoras manuales a la escritura poética. I (2911/1979, 10pm.)", desarrolla ampliamente el recurso de la "combinatoria de signos", al repetir hasta la saturación las posibilidades de mezclar aleatoriamente signos verbales y numéricos en una taxonomía que reduce a su mínima expresión las posibilidades del alfabeto occidental. Como en este caso:

\begin{tabular}{|c|c|c|c|}
\hline W & XVIII. & Código 1: morfología & \\
\hline $\begin{array}{l}X \\
Y\end{array}$ & & Código 2: consonantes & Motor de reterrorialización \\
\hline & & Código 3: sintaxis & \\
\hline Z & XIX. C & rtografía & \\
\hline & & + & Motor de desterrorialización \\
\hline & & rosodia & \\
\hline & $\mathrm{XX}$. & $\begin{array}{l}\text { 1. artículo } \\
\text { 2. sustantivo }\end{array}$ & \\
\hline & & 3. adjetivo & Variables \\
\hline & & 4. pronombre & \\
\hline & & 5. verbo & \\
\hline & XXI. & 6. adverbio & \\
\hline & & 7. preposición & Invariables \\
\hline & & 9. disyunción & \\
\hline & & & \\
\hline
\end{tabular}

Se aprecia en el ejemplo el desarrollo de estructuras complejas, como ecuaciones morfosintácticas irregulares, que sostienen el formato de un texto informativoexplicativo para aprender ciertas normas del código restringido de uso de la lengua. Como si fuera un manual de morfosintaxis, el poeta-gramático enseña aquí las 
partes de la oración, restringiendo el texto a un lenguaje especializado, técnico. Del mismo modo, pero extremando el recurso de la enumeración y la acumulación lingüística, el fragmento nueve de la misma sección, "Programa para combinatoria de 12 signos", reproduce doce figuras geométricas bajo la forma de un cuadrado, que intenta representar gráfica y visualmente las posibilidades de combinatoria de estos doce signos. La combinatoria, en este caso, en tanto que estructura, apunta a definir las posibilidades sintáctico-semánticas que un solo conjunto significante puede establecer a partir de los signos numérico-verbales que reproduce:

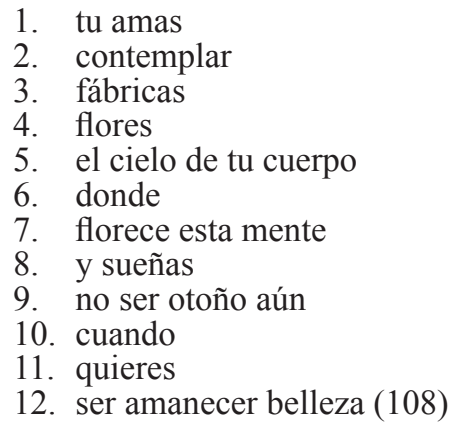

Los doce enunciados lingüísticos de esta estructura, que subrayan el carácter aleatorio del texto, se ven antecedidos por otras doce posibilidades matemáticas: un listado de operaciones de multiplicación que ponen a prueba las competencias o el saber matemático especializado del lector:

3: a) $\begin{array}{rrrrrr}1 \times 1 & 5 \times 6 & 9 \times 10 & 1 \times 2 & 8 \times 10 & 5 \times 1 \\ 2 \times 3 & 6 \times 7 & 10 \times 11 & 2 \times 4 & 10 \times 12 & 1 \times 3 \\ 3 \times 4 & 7 \times 8 & 11 \times 12 & 4 \times 6 & 12 \times 2 & 3 \times 6 \\ 4 \times 5 & 8 \times 9 & 12 \times 1 & 6 \times 8 & 2 \times 5 & 6 \times 9 \\ (107) & & & & & \end{array}$

Aunque, sin duda, más extrema por su nivel de codificación es la representación de esta combinatoria plurisignificativa de signos, mediante las distintas variables geométricas de un cuadrado y su correlato numérico-verbal (el mismo que veíamos en el ejemplo anterior), en una serie numerada de enunciados lingüísticos que pueden ordenarse o desordenarse según los cuadros sintagmáticos que elija el lector para formar la oración:

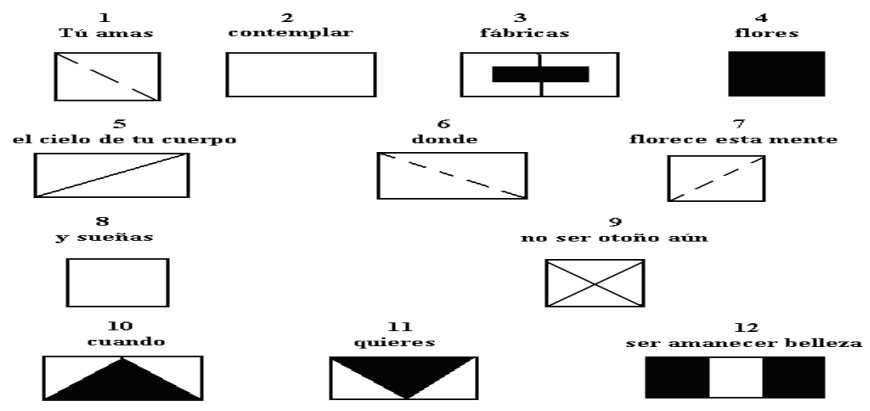

(112) 
El juego, en este caso, apunta directamente a las operaciones de la poesía concreta y su vertiente del poema-proceso al enfatizar el espacio gráfico como agente estructural; esto es, aquello que permite la formación de una estructura de signos según distintas posibilidades combinatorias. El lector puede jugar con estas posibilidades en la medida en que los doce signos proliferan en la significación de otros múltiples signos-enunciados y, así, la noción misma de signo lingüístico y visual (palabra e imagen) va expandiendo sus alcances hacia la apertura de otros significantes con los cuales construir tantos significados posibles como posibilidades combinatorias haya dentro de la estructura.

En sus filiaciones con la poesía concreta, estos ejercicios (ejemplo de los varios de este tipo en Angelus Novus) reproducen símbolos geométricos (triángulos, circunferencias, ángulos), así como la página en blanco en tanto que códigos noverbales pero en "clave lexical", valga decir, posibles de traducir en palabras. Verástegui retoma el juego matemático de la combinatoria; aquí, símbolos y códigos se incorporan al texto verbovisual como signos gráficos en un conjunto legible a través de un orden serial; de manera que es a partir de la sintaxis espacial y visual que se produce la composición gráfico-semántica del texto. El poema como producto resulta combinatoria, estructura, conjunto, proceso, ideograma, juego, pero requiere una sintaxis o un cierto ordenamiento en unidades discretas para su lectura. Las formas o símbolos que lo componen demandan claves léxicas para ello, o, en otras palabras, la necesidad de "traducir" el poema a códigos verbales; de manera que la correspondencia entre expresión visual y semántica se conjuga en una única estructura, asimilándose con la expresión gramatical de distintos códigos. El efecto resultante es el de movimiento y dinamismo infinito y desbordante de la estructura misma.

Pero no solo en los textos de Leonardo, también en otras secciones de Angelus Novus el hablante verasteguiano juega con la espacialidad/visualidad de la página y el desplazamiento e intercambio de los signos verbales y matemáticos, deconstruyendo así el purismo de sus respectivos lenguajes y códigos. El poeta ha sometido el lenguaje a un campo de pruebas, de exploraciones y de variaciones técnicas, a riesgo de obtener como producto no solo poemas heterogéneos desde el punto de vista genérico, sino también ambiguos, crípticos, herméticos, incomunicables, imposibles, en algunos casos, de decodificar o de comprender desde la sola lectura. En Angelus Novus, el sujeto poético ha hecho uso (y abuso) del recurso de la acumulación y saturación lingüística por el principio de repetición/variación de enunciados con cierta autonomía semántica, que, por momentos, semejan la estructura y función de una salmodia, un aforismo o un silogismo filosófico, para expresar, al final, una misma idea, la de que el mundo de la experiencia es una relación matemática y verbal, "como una máquina sintética" (Verástegui 1990: 211-2) que el poeta, cual angelus novus, debe descifrar y comunicar a la comunidad cultural de referencia. En esta obra integral, la sintaxis de carácter acumulativo, más el entramado conceptual de referencias eruditas, no hacen desaparecer al sujeto de la enunciación, sino que lo confirman como hacedor de una poética total (léase, experimental, concreta, referencial, ensayística), cuyos juegos de estructuras (sobremanera, cognitivos), dan cuenta de esa poiesis autoconsciente que es el poeta en tanto que memoria autoconstruida por un acervo que se quiere total de conocimiento y experiencia.

La última sección de "GALAX/DELEUZE" (Angelus Novus I), "5. Síntesis. Estructura/quark”, actúa como una suerte de epílogo del libro, donde el hablante 
explica el sentido de las estructuras empleadas (cuadros, esquemas, pentagramas, ecuaciones, diagramaciones) como "tautologías posibles" del homo ludens u homo faber que ha operado a lo largo de cada una de las estructuras del texto. Alude a la lógica de las correspondencias o equivalencias entre palabra y cosa, individuo y mundo, experiencia y representación, asumiendo, una vez más, el rol del poetagramático como artífice de un juego lingüístico-matemático que ofrece varias posibilidades de combinación y (de)codificación: “40: [...] En cada combinación: un poema distinto. En cada poema: el espejo de lo fugaz. El mundo no es sino un sistema de relaciones: un (simple, maldito) sistema. El mundo es una relación primordialmente verbal — como una máquina sintética" (1990: 212). Como su genealogía crítica de artistas contemporáneos, la Bauhaus, Kandinsky, Malevich, Le Corbussier, el ángel de la Anunciación, Enrique Verástegui ha buscado integrar el concepto de humano a la técnica, estando convencido de que "las formas que cambian / transfiguran los conocimientos marchitos / pero el hombre, homo ludens o faber / permanece" (Verástegui 1990: 348). Probablemente la clave de su proyecto integral esté en comprender los alcances de la proposición: "En cada combinación un poema distinto".

\section{JuAn Ramírez Ruiz: poesía InTEGRAl, POESÍA COMBINATORIA, LENGUA HANAN}

En 1975, en una entrevista realizada por el poeta Juan Cristóbal, Ramírez Ruiz explicaba:

Pienso que una poesía total estaría constituida por un cortejo de formas y por una sinfonía de significaciones reunidas en libro. Pues creo que se trata de escribir el libro que ponga en juego toda la inteligencia y toda la sensibilidad. Un libro visual, táctil, verbal, un libro para todo el cuerpo, capaz de integrar la forma que contenga versos cubiertos de capas de pensamientos y a los cuales se llegue luego de atravesar una por una esas capas. Cada sector de esa forma será una convergencia de rostros que activen todos los sentidos del lector (Cristóbal 2009).

Poco antes, en una conversación con Wolfgang Luchting, comentó, en un sentido semejante, su proyecto de escribir "un libro para todo el cuerpo. [...] Escrito con todos los signos, un libro donde el mundo ensaye su proyecto, dé una imagen del mundo por alcanzar, y desencadene ese deseo de lograrlo" (Luchting 1977: 298). Aunque Ramírez Ruiz no menciona la "poesía integral" (habla, más laxamente, de "poesía total"), resulta claro que la tenía presente, como parece confirmarlo el que en el 2006 afirmara que "[e]n la poesía integral se convocó a todos los componentes posibles, visuales y auditivos" (Ojeda 2008).

Estos componentes, así como la multidimensionalidad de los signos que alude al hablar de "un cortejo de formas y [...] una sinfonía de significaciones" y de la "convergencia de rostros que activen todos los sentidos del lector", no resultan tan claros en sus entregas poéticas iniciales. Él mismo declara, sobre de la continuidad de su proyecto, que fue "replanteando modos de expresión que progresivamente fueron convirtiéndose y transformándose en estaciones mucho más plenas, más complejas, más placenteras, más dinámicas y polidimensionales hasta entregar 
visiones estéticas completas, novedosas y originales" (ibid). No obstante, pueden reconocerse insinuados en, por ejemplo, las "ilustraciones" de Un par de vueltas de vueltas..${ }^{13} \mathrm{o}$, en algunas secuencias en que prima lo sonoro en el poema que da título al poemario ${ }^{14}$. Más adelante, se plasman ya nítidamente en Vida perpetua (1978), conjunto experimental que aborda las posibilidades de la poesía combinatoria y apuesta, en algunos textos, por el papel del lector como coautor que ejecuta, en cada operación de lectura, una nueva versión de estos, entendidos, así, como partituras abiertas a múltiples posibilidades de re-creación ${ }^{15}$.

Es evidente que la noción de poema integral o total con que trabaja Ramírez Ruiz en esos momentos implicaba más dimensiones que las involucradas en Un par de vueltas... Pero es en Las armas molidas en donde plasma de manera incluso más compleja y ambiciosa la estética del poema integral que no dejó nunca de trabajar. En este libro retoma y radicaliza líneas centrales de sus indagaciones previas: por un lado, los planteamientos iniciales respecto de la plasmación de la realidad en el texto (aunque ahora, con la multidimensionalidad involucrada, la realidad se concibe de modo más amplio), de la capacidad de la poesía de contribuir a la emancipación del individuo y la sociedad, y de la coexistencia de géneros diversos. También la importancia de lo visual y lo auditivo, así como la condición creadora del lector, exploradas en Vida perpetua, incluyen nuevas vías, pues Las armas molidas no se detiene en la poesía combinatoria por la que cada texto es una suerte de máquina poética inagotable, sino que propone, incluso, una nueva escritura ("Lengua Hanan") que no debía limitar sus posibilidades de aplicación en la poesía, pues se ofrece, utópicamente, como lenguaje modelo para nuevas escrituras nacionales que permitan nuevas formas y estructuras para pensar el país ${ }^{16}$.

En cuanto a sus contenidos semánticos, el libro propone un trayecto $-\mathrm{o}$ un "rumbo"-, desde una situación de guerras diversas (de conquista, dominación, exterminio, destrucción cultural, guerra interna) hacia otra de plenitud, justicia y "armas molidas", como anuncia el título. En paralelo, va exponiendo otro recorrido: su propuesta de escritura (hanan) como "instrumento ontológicamente nuestro" (195) cuyas bases (andinas), componentes y equivalencias se presentan gradualmente en el

13 Dos poemas ("Ilustración No. 1" e "Ilustración No. 2") en que el hablante exhorta a su interlocutor a seguir fiel a la relación arte-vida y a la creación de la "nueva belleza [que] es un problema colectivo", a la vez que lo advierte contra la "tranquilidad" como una "trampa". Cada poema, lleva, arriba y abajo, el título, colocado en cada posición a modo de reflejo invertido respecto de la otra.

14 "Tratún balzaan perotunin S D I 478 h P-saresne precopun asussem ay ay / jarajá jarajó poroun jarajá Amormío tu jarah oh alegría oh alegría 2543-27 / H P salud defesave tratunuti barengan Ay Ay Ay jarajá jarajó uh uh tratrá / Amor mío amor mío amor mío crehunde maharen pruncenece uh uh ay" (1971: 101).

15 Unos años antes de su aparición, en una carta a Octavio Paz publicada en Plural No. 48, en 1975, Ramírez Ruiz afirmaba, respecto de un texto poético que también le envía (y luego incluye en Vida perpetua): "El texto me sugiere la idea de instaurar estructuras flexibles, textos infinitos, abiertos en todas las direcciones, que liquiden la convención del inicio y final de un poema. [...] [D] e esta manera se afirma el principio de libertad [...] que se comparte al ofrecer el texto para la producción de cualquier nuevo texto. Por este camino, el poema se instituiría partitura, y la lectura un acto creador objetivo, "físico". // [...] Y se une al intento de destrucción del mito de la inmovilidad de la escritura. // Digo lo anterior porque creo que también en la página el mundo ensaya sus proyectos. Y porque la página es la zona donde una persona ha de entregar anticipos de libertad" (1975: 81).

16 En el "Índice tres" del libro afirma que los signos de la lengua hanan "constituyen una evidente larva de nueva escritura para hablar, poetizar, musicalizar, inventar colores, diseñar software geométricos y producir ritmos numerológicos y cálculos algorítmicos y algebraicos..." (194). 
área superior de la mayor parte de las páginas del libro. Ambos aspectos (el horizonte utópico de plenitud y la utópica lengua cuya escritura se propone) son denominados, sobre la base de la cosmovisión andina, "Hanan": "Nación Hanan" y "Lengua Hanan".

\section{Rumbos EN PARALELO: ESTRUCTURAS Y ESCRITURAS EN LAS ARMAS MOLIDAS}

Las armas molidas está organizado en tres secciones: primero, un "Prólogo", compuesto por una serie de signos visuales (denominados "andigramas") procedentes de diversos "textos" indígenas prehispánicos o coloniales (quipus, pallares, tejidos, ceramios, dibujos), que aparecen en el área superior de las primeras páginas (figuras 1 y 2).

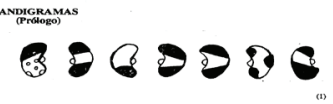

Figura 1

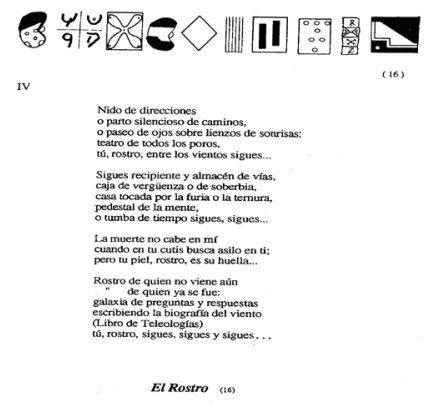

Figura 2

A continuación se presenta un conjunto de poemas en castellano, titulado "El Canto", organizado en tres partes y que incluye tres índices. El último de estos es un ensayo que explica, con fundamentos lingüísticos, semióticos, culturales e ideológicos, el proyecto de escritura del libro. La tercera parte es un epílogo titulado "Las Excursiones" que se divide también en tres bloques. Entre estos, escritos en lengua hanan, los dos primeros son series de poemas (Figura 3) y el último corresponde a dos páginas alusivas a los datos del autor. En lengua hanan está también la contratapa, que indica que este libro es "canto novela relato, crónica tratado biografía" (Figura 4).

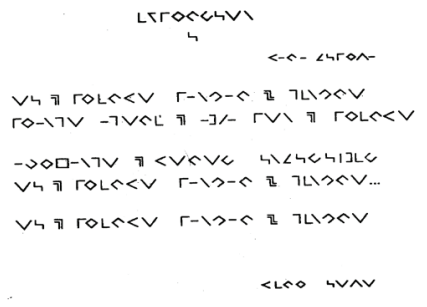

Figura 3

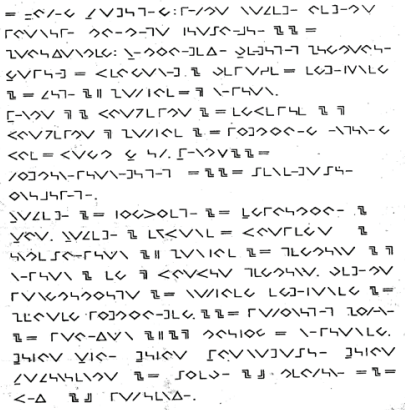

Figura 4 
Son los poemas en castellano de "El Canto", en la segunda parte del libro, los que de modo más evidente proponen el "rumbo", a través de la historia del Perú, desde una situación atravesada por guerras diversas hacia otra de plenitud. Cada sección de poemas presenta una estructura relativamente similar: los primeros textos son introductorios y presentan al "Hombre de armas molidas": el poeta-protagonista que es presentado tanto en primera como en tercera persona y asume la tarea de emprender el rumbo que permitirá vislumbrar la dimensión Hanan: la nación hacia la que utópicamente se encamina el país. Este hombre debe dejar constancia, dar testimonio y construir memoria, y se reconoce heredero de una genealogía inscrita en los procesos evolutivos originados en la formación de la naturaleza y de las diversas civilizaciones andinas, desde las más remotas, luego las preincas, la inca, las culturas indígenas y populares en la Colonia y la República, hasta el presente de la guerra interna peruana desde el que se enuncian los textos ${ }^{17}$. Como en sus libros anteriores, el poeta-protagonista se identifica con el autor, incluso con nombre propio, pero no deja de ser — pues su identidad es a la vez individual y múltiple — un hombre como todos: un golondrino ${ }^{18}$ que "[s]in vanidad ni modestia / no delante ni detrás de nada / y nadie" "reúne las partes más lejanas / y las une con las maneras de curar". Es, pues, sujeto común, trabajador e incluso una suerte de chamán, como sugiere Fredy Roncalla (2014): una voz y un individuo en que se funden muchas voces e individuos.

Luego de los poemas introductorios, cada parte de "El Canto" aborda los contextos de guerra atravesados. Se menciona que el "combate" se remonta a tiempos inmemoriales, previos incluso a los procesos de hominización, lo que implica, entonces, una lucha general por la vida: una única "guerra biótica" (1996: 60). No obstante, es claro que en esta guerra, en que lo más antiguo "está eslabonado /a los cadáveres recientes" (31), la conquista es un punto de inflexión, que explica incluso, al menos en parte, la continuidad de la violencia en el presente de enunciación. Los poemas inciden, por ello, en las rebeliones indígenas frente al sistema colonial, las resistencias andinas y amazónicas republicanas, las luchas obreras, las guerrillas de los años sesenta, la violencia senderista y la represión por parte del estado en los ochenta y noventa. Los nombres citados en esa revisión (Manco Inca, Túpac Amaru, Uchcu Pedro, Juan Pablo Chang o, entre muchos otros, Javier Heraud con su nombre de guerrillero: Rodrigo Machado) no dejan duda sobre el horizonte utópico emancipador que articula la mirada del hablante.

Estos "combates innumerables" (46) suponen muerte, dolor y desgarramiento, pero también rememoran, poniéndola en primer plano, la participación de quienes fueron mucho más que solo víctimas de la colonialidad: los que lucharon y resistieron dejando sus "gotas de futuro" en el largo rumbo hacia una situación y un tiempo

17 La "guerra interna" es el proceso de violencia política vivido en el Perú a raíz de la insurgencia de Sendero Luminoso frente al Estado peruano en 1980. El costo total de víctimas mortales hasta el año 2000, en que cae la dictadura de Alberto Fujimori, se calcula en cerca de 70000 (Comisión de la Verdad y Reconciliación [CVR] 2003). En Las armas molidas, la guerra interna es un proceso clave para entender la urgencia de un replanteamiento radical de las lógicas impuestas por la cultura occidental-colonial en desmedro de los modos de conocimiento y relación indígenas, que están a la base de su propuesta utópica (cf. Chueca 2014b).

18 Unos versos de lectura en paralelo presentan a los golondrinos como "campesinos obreros guerreros /bajo bloques de lana /eventuales /y edificios cernidos como horizontes /cachueleros yanaconas apareceros /mi mente vuelve y busca sosiego en mí /enganchados braceros ambulantes / y ya en mí- le encargo a mi mente /explotados correspiradores / que te me diga qué está pasando ahí" (26, cursivas nuestras). 
distintos. Sus nombres permiten señalar otro aspecto central del libro: la revisión de cómo se han escrito las historias. Aquí Ramírez Ruiz va más allá de los esfuerzos por desmontar las narraciones y los heroísmos oficiales. Ello ocurre por supuesto, como se desprende de que no aparezca ninguno de los "libertadores" emblemáticos ni de los más conocidos héroes de la Guerra del Pacífico, y que se mencione, en cambio, a los citados y a tantos más, aun menos conocidos. Pero el hablante recuerda además con insistencia que son muchos los héroes anónimos que no puede nombrar: "Quiénes además de Cahuide- [...] cómo se llamaban... //[...] ¿Solo Rumirato y Perote se inmolaron / unidos a Juan Santos Atahualpa? //[...] Qué padres no tienen su héroe- /qué familia no tiene su mártir" (33).

El tercer momento en cada bloque de poemas presenta la visión utópica: la posibilidad de vislumbrar y acercarse a Hanan. En el caso de la última sección, en que la resistencia frente a la muerte que se expande parece tener menos posibilidades, tanto por la violencia senderista como por la estatal, llama la atención la mayor proximidad a la "Nación Hanan" presentada como casi inminente. Esto podría explicarse, a partir de la necesidad de insistir en la urgencia de un replanteamiento de los modos de conocimiento, de pensamiento y de relación entre los miembros de la comunidad peruana.

Como quedó señalado, en paralelo al "rumbo" trazado por "El Canto", el libro va exponiendo otro recorrido: la propuesta de la escritura hanan. Esta comienza a explicarse en el "Prólogo" (Figura 1), en el área superior de las páginas iniciales y continúa en varias de las que corresponden a "El Canto" (Figura 2). En esa misma zona aparece luego "La Huella", que ofrece algunos diagramas y a continuación los grafemas (que componen el "alfagrama"), fonemas y morfemas de la escritura hanan con sus equivalencias en castellano. Esto se sintetiza en un cuadro en el Índice 3 (Figura 5) que, recordemos, es un ensayo sobre dicha lengua. En la parte superior de las páginas de "El Canto" se indican también las correspondencias de varios de dichos signos con números, notas musicales (Figura 6), signos matemáticos y colores (Figura 7).

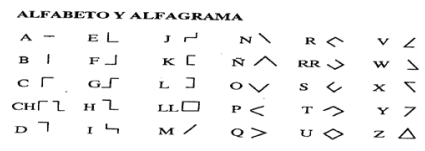

Figura 5

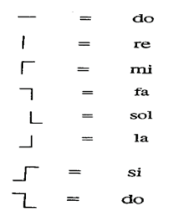

Figura 6

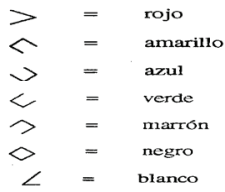

Figura 7

Lo anotado hasta aquí permite algunas observaciones importantes. Primero, la presencia de la cosmovisión andina en la organización y plasmación del libro. Sobre esto es clara la mención de "Hanan”. En el índice 3, además, se explican como fundamentales el par de opuestos complementarios: Hanan Pacha/Hurin Pacha y la tríada Uku, Kay y Hanan Pacha. En los poemas aparecen además las palabras quechuas "Tinkuy" (reunión o confluencia, y también encuentro tensional) y "Tinkunakuy" (hermanarse, converger), y se puede reconocer la alusión al Pachacuti o al mito de Inkarrí $^{19}$. En una nota que anunciaba, en 1994, la aparición del libro, Tulio Mora

9 Para un desarrollo amplio al respecto, véase Chueca 2014a. 
relacionó las categorías de Hanan y Hurin Pacha con los espacios de arriba y abajo en la composición de las páginas. Esta correspondencia puede complejizarse: Hanan Pacha, explica Ramírez Ruiz, corresponde al espacio-tiempo que expresa la "suprema culminación de los procesos del protoplasma, de la biósfera, del cosmos, manifestada en diáfanas teleologías producidas por el hombre" (1996: 191). Hurin Pacha, por su parte, "expresa los procesos sociales y naturales, la biósfera de la superficie terrestre, del suelo y del subsuelo, la historia, el cuerpo, el ciclo del tiempo en sus fases claridad y oscuridad, la cronología y los eventos" (ibíd.). En este sentido, la escritura de abajo (poemas en castellano) que constituye "El Canto" se dirige o tiene como horizonte (y proyecto utópico) la de arriba, que es, como sugirió el poeta, aquella que puede expresar más cabalmente la plenitud vislumbrada y el rumbo hacia ella.

Hay continuidad entre los "andigramas" y los "alfagramas" de la escritura hanan. Ramírez Ruiz señaló que los alfagramas resultaron de un proceso de esquematización a partir de aquellos. Los andigramas son signos visuales, pero también se mencionan como "escritura": "[s]ignos, logogramas y símbolos de los diversos sistemas escriturales labrados por el hombre" (1996: 189). Esto permite reconocer una propuesta fundamental del libro: el cuestionamiento de lo que Martín Lienhard llama "fetichismo de la escritura": la concepción casi sagrada de la alfabética como única escritura, que fue introducida por los europeos con la conquista e interiorizada por los indígenas como consecuencia de la dominación. Lienhard, contra la creencia de un continente ágrafo, afirma la existencia de otras escrituras en América prehispánica y explica que estas tendían, en general,

no a transcribir discursos verbales, sino a plasmar el mundo cósmico, natural y social en cuadros o listas. [...] no transcriben el movimiento de la inteligencia discursiva del hombre, sino que ofrecen, bajo forma sintética, el resultado de sus observaciones, reflexiones y medidas. La dinámica del discurso humano, y este punto nos parece decisivo, se desarrolla bajo el signo de la oralidad. Sin duda, la cosmología, la administración (económica, demográfica, tributaria, ritual, jurídica) y la cronología histórica se hallan consignadas en las listas o los cuadros de los códices o en los nudos, las posiciones y los colores de los kipu. (1992: 37-38).

La violencia cultural y simbólica de la "imposición arbitraria de la escritura alfabética" (41) sobre las modalidades de escritura existentes en América y sobre la importancia de la oralidad representó un aspecto clave de la justificación y configuración de la jerarquía racial-étnica y de la división internacional del trabajo (centro-periferia) propias de la "economía-mundo capitalista" fundada con la conquista de América: lo que Aníbal Quijano, desde una postura decolonial, ha denominado "colonialidad del poder": la dimensión constitutiva del proyecto eurocentrado de modernidad cuyas consecuencias siguen operando hasta hoy. El hecho de que Ramírez Ruiz se refiera a los andigramas como escritura, y proponga una escritura otra, que incluye dimensiones como las cromáticas y las musicales, además de que mencione saberes indígenas como "libro zambo", "libro cholo" o "libro indio", evidencia su cuestionamiento de algunos de los principios fundamentales de la subalternización de conocimientos propia de la colonialidad, lo que Walter Mignolo explica como "colonialidad del saber"20.

La “colonialidad del poder", sostiene Quijano, "es uno de los elementos constitutivos y específicos del patrón mundial de poder capitalista. Se funda en la imposición de una clasificación racial/étnica de la población del mundo como piedra 
La presencia de los andigramas y de los espacios de arriba y abajo evidencian la gran importancia de la visualidad en Las armas molidas. Esto, sumado a la posibilidad de múltiples lecturas de los poemas expresada en la organización alternativa del conjunto según lo establecido en los dos primeros índices, y a partir de las llamadas "paligadas" ("palabras ligadas que imantan un espacio semántico múltiple”, según explica el autor) o de las resonancias musicales y cromáticas en los poemas en lengua hanan; y aunado también a que algunos títulos están al final de los poemas y en otros casos al inicio, y a varios otros procedimientos que alteran la lógica occidental de la lectura, nos acerca a un libro que "ya no se puede leer, apenas, de izquierda a derecha, hay que leer en todas direcciones y según distintas posibilidades" (Jiménez 2014: 90). La poética integral concebida aquí por Ramírez Ruiz es indesligable de estos rasgos.

El caso de las paligadas es muy importante porque permite reconocer estrechos vínculos entre la escritura en castellano y en lengua hanan. Ramírez Ruiz indicó que las paligadas son "palabras ligadas que imantan un espacio semántico múltiple” y que "están constituidas [...] por los componentes de cinco categorías gramaticales: artículo, pronombre, conjunción, adverbio y preposición; intercalados o relacionados entre sí" (197). En los poemas en castellano es posible reconocer una muestra de esto en el verso de "Un día y un Poeta", en que se lee: "El tu mi Perú próximo hanan, escucha". La coexistencia en la oración de "El" "tu" y "mi" permite lecturas alternas o simultáneas. En el caso de los textos en hanan, la propuesta es más compleja, pues una misma paligada, al utilizarse con valor de morfema gramatical, puede corresponder, por ejemplo, a un adverbio o una preposición, simultánea o alternativamente. Así, el signo “ $\mathbf{7}$ ” (que equivale como fonema a /d/), al utilizarse como morfema gramatical corresponde a pronombres posesivos, a las contracciones "al" y "del" y a conjunciones subordinantes o adverbios de orden. Por su parte, el signo “ ”. (que como grafema es “h”), desde la gramática puede ser pronombre indefinido, proposición subordinada o relacionante, preposición compuesta o adverbio pronominal demostrativo. Estas explicaciones son fundamentales para la lectura de los poemas de "Las Excusiones" (primera serie en hanan), en que el lector debe elegir, entonces, cuáles son los enlaces gramaticales que corresponden al texto, en función de la adecuación sintáctica a la frase u oración, o multiplicar las lecturas considerando de forma alternativa o simultánea las diversas posibilidades de lectura. Veamos lo que sucede en el primer verso de la "Excursión 1":

\section{Vh 7}

La equivalencia grafémica da como resultados: "Vi “行” cuerpo cantar “ $\mathbf{L}$ " dentro". Al pretender completar la lectura, y limitándonos solo a las posibilidades concordantes sintáctica y semánticamente con el resto de la frase, podríamos tener: "Vi mi/tu/su cuerpo cantar desde/hasta/hacia/para dentro" o "Vi mi/tu/su cuerpo

angular de dicho patrón de poder, y opera en cada uno de los planos, ámbitos y dimensiones, materiales y subjetivas, de la existencia cotidiana y a escala social (2007: 93). Santiago Castro Gómez explica que "Quijano usa la noción de 'colonialidad' y no la de 'colonialismo' [...] para llamar la atención sobre las continuidades históricas entre los tiempos coloniales y los mal llamados tiempos 'poscoloniales'; y [...] para señalar que las relaciones coloniales de poder no se limitan solo al dominio económico-político y jurídico-administrativo de los centros sobre las periferias, sino que poseen también una dimensión epistémica, es decir, cultural" (2007: 19): la "colonialidad del saber" de Mignolo. 
cantar aquí/allí/ahí dentro", con lo que tenemos, para este solo verso, veintiún lecturas distintas posibles, que, como indicamos, pueden considerarse como alternativas o simultáneas. Cada una de ellas, aunque los sentidos no varían demasiado, supone sí sujetos, posiciones o lugares distintos. Esta propuesta —análoga, aunque más radical a la de Vida perpetua, en que en algunos poemas el lector debía combinar las partes del texto según su propia decisión, con lo que cada operación de lectura da como resultado un texto diferente y colocaba al lector como coautor del texto que construye/decodifica - es la que opera también en los casos de las paligadas de la escritura alfabética en castellano y lo emparenta con procedimientos como los del poema/proceso de la poesía concreta, ensayada en Verástegui en sus ejercicios combinatorios de Angelus Novus. A esto hay que añadir que los signos del alfagrama se correlacionan también con colores, notas musicales o números, lo que permite que al leer un poema en hanan el lector perciba resonancias cromáticas o musicales.

Otros aspectos, en los poemas en castellano, que contribuyen a percibir la dimensión de poesía integral que alcanza Las armas molidas son las posibilidades de su organización en "El Canto" y las inflexiones e infracciones que se observan en ellos al compararlas, incluso, con prácticas habituales en la poesía contemporánea. Cada una de las secciones de poemas presenta, como se apuntó más arriba, dos modos paralelos de estructurarse, plasmados respectivamente en los índices "uno" y "dos". Según el "Índice uno", la "Primera Parte" de "El Canto" presenta veinticuatro poemas, la segunda dieciocho y la tercera veintiocho. Los títulos de estos se encuentran escritos en negritas y en cursivas al final de cada poema. Desde esta perspectiva, lo único inhabitual sería el hecho de que los títulos estén al final y que la paginación no se presente en el margen superior o inferior de la página, sino entre paréntesis al lado de los títulos de cada poema. En cuanto a la organización propuesta por el “Índice dos", los textos están numerados en romanos, del I al XXXVI en la primera parte, y del I al XXXIII tanto en la segunda como en la tercera. Algunos de estos presentan, a su vez, divisiones internas.

En algunos casos, los poemas o las partes de estos están divididos en bloques que corresponden a una estrofa o a un conjunto de ellas, que aparecen numerados, en arábigos, en el margen izquierdo. A veces, estos bloques están subdivididos, para lo que se emplean los decimales. El hecho de que no todos los poemas presenten estos bloques numerados y que la numeración de estos sea correlativa (del 1 al 305) podría sugerir, como otra posibilidad de lectura, una que considere únicamente los bloques numerados, dejando sin leer los otros como si fueran 'poemas prescindibles' al modo de los “capítulos prescindibles" de Rayuela de Cortázar. Esta mención no es gratuita, pues, siguiendo lo que Ramírez Ruiz ya había ensayado en Vida perpetua, pone al lector en la condición de coautor que debe crear su propia versión del libro que, así, se propone inagotable, algo ya observado a partir de la posibilidades ofrecidas por las "paligadas" en la escritura hanan. Se observan también, en algunos poemas, llamados de notas a pie de página, identificadas con letras (A, B, C...), que aparecen al final de cada uno de ellos. Se trata en este caso de fragmentos poéticos: estrofas o series de estrofas que, a diferencia de lo que ocurre, por ejemplo con las notas explicativas que aparecen al final de The Waste Land de Eliot, deben verse, más bien, como extensiones o ramificaciones de los textos.

De estas maneras, la escritura de Las armas molidas busca captar y sugerir lo que Ramírez Ruiz llamó el "vértigo multidimensional de la existencia" (194): la percepción de varios planos simultáneos a partir de los mismos signos presentados 
que impiden que la lectura pueda ser solo lineal. Como indicó el poeta, esta escritura, que apunta en última instancia a expresar la dimensión Hanan de la existencia configurada en las teleologías de plenitud y "armas molidas", debe considerarse "sintética, aglutinante, holosemántica y epifánica, [que] imante e irradie instintos de iluminación, sabiduría, conocimiento, solidaridad, sosiego, ternura, juego o belleza" (1996: 191). Queda claro, pues, que la escritura hanan representa un cuestionamiento y un desafío profundos de la hegemonía de los principios, lógica y convenciones de las lenguas occidentales, y propone, frente a ello, un sistema que coloca en primer plano otros modos de conocimiento.

Se puede concluir, entonces, que la plasmación de la poética integral en Las armas molidas conduce a configurar un libro multidimensional en que el lector debe ser coautor, y en que la materialidad de los signos se pone en primer plano, de modo que se aproxime al ideal de "libro visual, táctil, verbal, un libro para todo el cuerpo" que expresaba Ramírez Ruiz desde mediados de los setenta. Para esto, como se ha podido percibir, el poeta, continuando su aventura poética, ha radicalizado algunas de las posibilidades exploradas por las experiencias vanguardistas y neovanguardistas, de las que se nutre, pero de las que también se distancia a partir de su inmersión en configuraciones culturales que ponen en cuestión principios fundamentales de la razón occidental. Las armas molidas establece, así, un enriquecedor diálogo entre lo más renovador de la poesía contemporánea y la mirada decolonial que busca darle énfasis a las cosmovisiones indígenas como punto de partida de su proyecto. Un proyecto en que la reconfiguración de los sentidos y percepciones de "lo nacional" resultan fundamentales.

\section{A MODO DE CONCLUSIÓN}

En el marco del horizonte utópico y total que buscaba la poética integral de HZ, Enrique Verástegui logró materializar dicha estética mediante un "arte concreto" o un "poema-proceso" que, desde la autoconstrucción de la figura del poeta moderno, articulaba sus bases a partir de la multidimensionalidad del conocimiento que promovía, desde el discurso, la integración de saberes, lenguajes y formas artísticas diferenciadas. Algo semejante es lo que realiza Ramírez Ruiz desde una propuesta que contempla no solo un lenguaje poético que explora géneros, registros y soportes diversos, así como posibilidades combinatorias, sino desde una lengua otra (Hanan), creada a partir de la indagación de racionalidades, modos de conocimiento, pensamiento y relación intersubjetiva indígenas. En ambos casos, los desarrollos de las nuevas posibilidades de la estética del poema integral —que amplían decisivamente los planteamientos horazerianos de la primera hora acerca de la realidad y de su posible representación - involucran la persistencia de la dimensión utópica como componente fundamental. Angelus Novus viene a confirmar que el poeta integral es aquel que se siente llamado a desarrollar tanto una labor estética de creación de la belleza mediante la palabra, como a cumplir un compromiso social utópico: de testimonio, reivindicación y transformación del mundo y la realidad social y vital, pues el poeta guarda un don profético (el "aura” del sujeto romántico), siendo el trabajo con la palabra no solo experimento y oficio, sino también designio, iluminación, vaticinio. En Las armas molidas, por su parte, la figura del poeta- 
golondrino-chamán, simultáneamente individual y colectivo, permite reconocer la confianza en la poesía en el proceso de transformación del individuo y de la sociedad, aun a pesar de las dificultades de imaginar un horizonte abierto, como ocurría en el contexto de la violencia peruana de los años ochenta.

\section{OBRAS CITADAS}

Benjamin, Walter. 2007. Conceptos de filosofia de la historia. La Plata: Terramar.

Castro-Gómez, Santiago y Ramón Grosfoguel. 2007. "Prólogo: Giro decolonial, teoría crítica y pensamiento heterárquico". El giro decolonial. Reflexiones para una diversidad epistémica más allá del capitalismo global. Eds. Santiago Castro-Gómez y Ramón Grosfoguel. Bogotá: Siglo del Hombre, Universidad Central y Pontificia Universidad Javeriana. 9-23.

Chueca, Luis Fernando. 2006. "Alcances y límites de la propuesta vanguardista de Hora Zero". Intermezzo Tropical 4: 29-45.

2014a. "'Hanan=Nación de Armas Molidas". 'Reescritura', guerra y nación en Las armas molidas de Juan Ramírez Ruiz". Revelación en la senda del manzanar. Homenaje a Juan Ramírez Ruiz. Ed. Fredy Roncalla. Lima: Pakarina editores y Hawansuyo. 151-165. 2014b. "Las armas molidas de Juan Ramírez Ruiz: reescritura poética decolonial de la nación peruana en tiempos de guerra". Revista de Crítica Literaria Latinoamericana 80: $282-308$.

Comisión de la Verdad y Reconciliación (CVR). 2003. Informe Final. http//www.cverdad.org. pe/ifinal/index.php.

Cristóbal, Juan. 2009. "Entrevista (inédita) a Juan Ramírez Ruiz". Blog Ancash 444: aproximaciones a Juan Ramírez Ruiz. http://ancash444aproximacionesajuanram.blogspot. com/2009/11/juan-cristobalentrevista-indedita-juan.html.

De Lima, Paolo. 2014. "La Universidad de San Marcos, la Revolución y la "involución" ideológica del Movimiento Hora Zero. A veinticinco años de "Palabras urgentes (2)" de Juan Ramírez Ruiz". Revelación en la senda del manzanar. Homenaje a Juan Ramírez Ruiz. Ed. Fredy Roncalla. Lima: Pakarina editores y Hawansuyo. 119-129.

De Sousa Rodrigues, José. 1978. Concretismo. Lima: Centro de Estudios Brasileños.

Falla, Ricardo. 1990. Fondo de fuego. La generación del setenta. Lima: Concytec.

Fede, Alba Delia. 2013. "Notas sobre algunas páginas de Splendor". Epistemología y épica de la complejidad. México: Proyecto Literal-Kodama, Cartonera-Logógrafo, EdicionesRatona Cartonera. 15-22.

Frisancho, Jorge. 1990. "Verástegui, el moderno". Hueso Húmero 26: 117-121.

Foucault, Michel. 1999. "Espacios diferentes”. Estética, ética y hermenéutica. Barcelona: Paidós. 431-434

Galindo, Óscar. 2013. "Neovanguardias hipervitalistas en la poesía hispanoamericana (19581976): nihilistas, revolucionarios, solidarios y amorosos". Taller de letras 52: 11-37.

Guillén, Paul. 2015. Poesía y psicoanálisis. Falo/Escritura en Enrique Verástegui. Lima: Perro de Ambiente.

2005. Poesía peruana contemporánea. 33 poetas del 70. Lima: Fondo Editorial Cultura Peruana.

2002. "Un cuerpo bien proporcionado es la imagen del universo: un diálogo con Enrique Verástegui”. Hispanic Poetry Review 10. Texas: Texas A\&M University. 84-106.

González Vigil, Ricardo. 1999. Poesía peruana del siglo XX (Tomo II). Lima: Ediciones Copé.

Hernández, Biviana. 2012. "Poesía y neovanguardia, notas para pensar un nuevo repertorio". Revista de Crítica Literaria Latinoamericana 76: 271-296.

Jiménez, Reynaldo. 2014. "Una conversación repentista con Juan Ramírez Ruiz". Revelación en la senda del Manzanar. Homenaje a Juan Ramirez Ruiz. Ed. Fredy Roncalla. Lima, 
Pakarina editores y Hawansuyo. 87-93.

Lienhard, Martin. 1992. La voz y su huella. Escritura y el conflicto étnico-social en América Latina. Lima: Editorial Horizonte.

López Degregori, Carlos y Edgar O’Hara. 1998. Generación poética del 60. Estudio y muestra. Lima: Universidad de Lima.

López Soria, José Ignacio. 2001. "Piedras de escándalo". Hueso Húmero 39: 168-171.

Lutching, Wolfgang. 1977. Escritores peruanos que piensan que dicen. Lima: Editorial Ecoma.

Matos Mar, José. 1984. Desborde popular y crisis del estado. El nuevo rostro del Perú en la década de 1980. Lima: Instituto de Estudios Peruanos.

Medo, Mauricio y Raúl Zurita. 2004. La letra en que nació la pena. Muestra de poesía peruana 1970-2004. Lima: El Santo Oficio.

Mignolo, Walter. 1982. "La figura del poeta en la lírica de vanguardia". Revista Iberoamericana 118-119: 131-148.

2007. "El pensamiento decolonial: desprendimiento y apertura. Un manifiesto". El giro decolonial. Reflexiones para una diversidad epistémica más allá del capitalismo global. Eds. Castro-Gómez, Santiago y Ramón Grosfoguel. Bogotá: Siglo del Hombre Editores, Universidad Central, Pontificia Universidad Javeriana. 25-46.

Mora, Tulio, ed. 2009. Hora Zero: los broches mayores del sonido. Lima: Fondo Editorial Cultura Peruana.

Mondragón, Sergio, Randall, Margaret y Harvey Wollin. eds. 1962. El corno emplumado / The plumed horn 1. México: Siglo XXI.

Ojeda, Rafael. 2008. "Juan Ramírez Ruiz: Yo no percibo la muerte como un evento de naturaleza social sino como algo de tipo ontológico. Entrevista". Ciberayllu. http://www. ciberayllu.org/Cronicas/RO_RamirezRuiz.html.

Oviedo, José Miguel. 1973. Estos 13. Poemas / documentos. Lima: Mosca Azul.

Pimentel, Jorge. 1970. Kenacort y Valium 10. Lima, Ediciones del Movimiento Hora Zero.

Quijano, Aníbal. 2007. "Colonialidad del poder y clasificación social”. El giro decolonial. Reflexiones para una diversidad epistémica más allá del capitalismo global. Eds. CastroGómez, Santiago y Ramón Grosfoguel. Bogotá: Siglo del Hombre Editores, Universidad Central, Pontificia Universidad Javeriana: 93-126.

Ramírez Ruiz, Juan y Jorge Pimentel. 1970. "Palabras urgentes". Hora Zero. Materiales para la nueva época. 7-10.

Ramírez Ruiz, Juan. 1971. Un par de vueltas por la realidad. Lima: Movimiento Hora Zero. 1975. [Carta a Octavio Paz y poema “Aplicación”]. Plural 48: 81-83. 1978. Vida perpetua. Lima: Ames. 1980. "Palabras urgentes (2)". Lima: 28 de agosto [volante a mimeógrafo]. 1996. Las armas molidas. Lima: Arteidea.

Roncalla, Fredy Amílcar, ed. 2014. Revelación en la senda del Manzanar. Homenaje a Juan Ramírez Ruiz. Lima: Pakarina editores y Hawansuyo. 17-34.

Sánchez Hernani, Enrique. 1981. Exclusión y permanencia de la palabra en Hora Zero: 10 años después. Lima: Ruray Editores.

Torres Rotondo, Carlos y José Carlos Yrigoyen. 2010. Poesía en rock: una historia oral. Perú, 1966-1991. Lima: Ediciones Altazor.

Verástegui, Enrique. 1989. Angelus Novus o libro de la virtud (Tomo I). Lima: Antares. 1990. Angelus Novus o libro de la virtud (Tomo II). Lima: Antares y Lluvia editores. 2013. Splendor. Epistemología y épica de la complejidad. México: Proyecto LiteralKodama Cartonera-Logógrafo Ediciones-Ratona Cartonera.

Villacorta, Carlos. 2011. "En los extramuros del mundo: muro y encierro en un poemario de Enrique Verástegui”. The Korean Journal of Hispanic Studies 4: 01-34.

Yurkievich, Saúl. 1984. "Los disparadores poéticos". A través de la trama: sobre vanguardias literarias y otras concomitancias. Barcelona: Muchnik. 45-52. 